\title{
Advanced age predicted risk for recurrent stroke after first-ever stroke
}

\author{
Hankey GJ, Jamrozik K, Broadhurst \\ Ri, et al Long-term risk of first re- \\ current stroke in the Perth Com- \\ munity Stroke Study. Stroke. 1998 \\ Dec;29:2491-500.
}

\section{Question} stroke, what are the risks for and the risk factors of a first recurrent stroke?

\section{Design} in the Perth Community Stroke Study (PCSS) with follow-up of 5 years.

\section{Setting}

Perth, Western Australia, Australia.

\section{Patients}

343 patients (mean age $73 \mathrm{y}, 53 \%$ men) with an acute, first-ever stroke who were living in the defined PCSS geographic area. Follow-up was $100 \%$.

\section{Assessment of prognostic factors}

Age; sex; marital status; living arrangements; level of independence before initial stroke; smoking; alcohol use; history of hypertension, angina, myocardial infarction, or transient ischemic attack; diabetes mellitus; intermittent
In patients with an acute first-ever

An inception cohort study of patients claudication; pathologic subtype, etiologic subtype, and clinical syndrome of initial stroke; and baseline mental state, incontinence, cardiac failure, atrial fibrillation, and clinical hypertension.

\section{Main outcome measures}

Mortality and risk for and pathologic subtype of a first recurrent stroke at 4 months, 12 months, and 5 years.

\section{Main results}

At 5 years, 199 patients $(58 \%$ ) had died. 52 patients $(15 \%)$ had had a first recurrent stroke, of which $12(23 \%)$ were fatal within 28 days; 37 strokes ( $71 \%$ ) were caused by cerebral infarction, 4 $(8 \%)$ were caused by primary intracerebral hemorrhage, and $11(21 \%)$ were of an undetermined cause. The 5-year cumulative risk for a first recurrent stroke was $22.5 \%$ (95\% CI $16.8 \%$ to $28.1 \%$ ), and the risk was greatest in the first 6 months after stroke $(8.8 \%, \mathrm{CI}$
$5.4 \%$ to $12.1 \%$ ). Multiwariate analysis identified that age between 75 and 84 years predicted a first recurrent stroke within 5 years of a first stroke; however, trends existed between hemorrhagic index stroke or diabetes mellitus and an increased risk for a first recurrent stroke (Table).

\section{Conclusion}

The risk for a first recurrent stroke was increased in patients with an acute firstever stroke who were between 75 and 84 years of age.

Soutces of fonding: National Healtb and Medial Researcb Council of Australia and Heathway, Health Promotion in Westem Australia.

For conrespondence: Dr. G.7. Hankey, Stroke Unit Detariment of Neurlogy, Royal Peith Hospital, GPO Box X2213, Perth, Westem Austatia 6001, Austratia. DAX 61-9-224-3511.

Abstract and Commentary also published in ACP Foumal Club. 1999;130:77.

Hazard ratios (HRs) of risk factors for a first recurrent stroke within 5 years of an index stroke

\begin{tabular}{lll}
\hline Risk factor & HR $(95 \% \mathrm{CI})$ & $P$ value \\
\hline Age 75 to $84 y$ & $2.6(1.1$ to 6.2$)$ & 0.02 \\
Hemorrhagic index stroke & $2.1(0.98$ to 4.4$)$ & 0.06 \\
Diabetes mellitus & $2.1(0.95$ to 4.4$)$ & 0.07
\end{tabular}

\section{Commentary}

This study is an important addition to our knowledge about recurrent stroke. Hankey and colleagues found that 1 in 6 persons who survive a first-ever stroke have a recirrent stroke in 5 years. As in other studies of recurrent stroke (1-3), the Perth group found the highest rate of stroke to occur within 6 months of the initial stroke. This emphasizes the importance of initiating preventive measures as early as possible after an initial stroke.

The $15 \% 5$-year rate of recurrent stroke is lower than the $25 \%$ to $30 \%$ rate reported in other studies (1-3). Hankey and colleagues suggest that this difference may be caused by a reduction in recurrent stroke with the recent widespread use of aspirin.

Hankey and colleagues report that age, hemorrhagic index stroke, and diabetes are risk factors for recurrent stroke, but only age ( 75 to 84 y) was sigrificant. Age and diabetes are known risk factors for recurrent stroke, but hemorrhagic stroke is not. This interesting finding needs further study.

Hankey and colleagues found that the subtype of a recurrent stroke was the same as that of the initial stroke in $88 \%$ of cases. However, this may not be tue of all stroke subtypes. A recent study showed that $42 \%$ of recurrent strokes are ischemic in patients with an initial cerebral hemorrhage and $52 \%$ of recurrent strokes are nonlacunar in patients with an initial lacunar stroke (4).

Mortality after a first-ever stroke is even more of a problem than the stroke itself. Other studies have found similar, but lower, 5 -year mortality rates $(45 \%$ to $53 \%)(2,3)$. Comorbid cardiac conditions seen to be the major determinant of this mortality (3).
Patrick Pullicino, $M D, P D D$ State University of New York at Buffalo Buffalo, New York, USA

Reforences

1. Burn J, Dennis M, Bamford J, et al Long-term risk of recurrent stroke after a first-ever stroke. Stroke. 1994;25;333-7.

2. Sacco RL, Shi T, Zamanillo MC, Karg wan DE. Predictors of mortality and recurrence after hospitalized cerebral infarction in an urban community: the Northern Manhattan Stroke Study. Neurology. 1994; 44:626-34.

3. Petty GW, Brown RD Jr, Whisnant JP, et al. Survival and recurrence after first cerebral infarction: a population.based study in Rochester Minnesota, 1975 through 1989. Nemrology. 1998;50:208-16.

4. Yamamoto $\mathrm{H}_{3}$ Bogousslavsky J. Mechanisms of second and further surokes. I Neurol Neurosurg Psychiatry. 1998;64:771+6. 